\title{
Molecular features linked to the growth-inhibitory effects of gemcitabine on human pancreatic cancer cells
}

\author{
HIROAKI TOSHIMITSU ${ }^{1,2}$, NORIO IIZUKA ${ }^{3}$, KOHTARO YAMAMOTO ${ }^{1}$, SHIGETO KAWAUCHI ${ }^{2}$, \\ ATSUNORI OGA ${ }^{2}$, TOMOKO FURUYA ${ }^{2}$, MASAAKI OKA ${ }^{1}$ and KOHSUKE SASAKI ${ }^{2}$ \\ Departments of ${ }^{1}$ Surgery II, ${ }^{2}$ Pathology II, ${ }^{3}$ Bioregulatory Function, Yamaguchi University \\ School of Medicine, 1-1-1 Minami-kogushi, Ube, Yamaguchi 755-8505, Japan
}

Received January 24, 2006; Accepted April 6, 2006

\begin{abstract}
Although gemcitabine (GEM) is widely used in the treatment of pancreatic cancers, the molecular mechanisms that underlie its anti-tumor effects are not fully understood. To clarify the anti-tumor mechanism(s) of GEM, we studied a human pancreatic cancer cell line, YPK-1, that showed a 50\% inhibitory concentration (IC50) of GEM of $6.3 \times 10^{-3} \mu \mathrm{g} / \mathrm{ml}$ after $72 \mathrm{~h}$ of exposure. Cell proliferation was perturbed by 6 to $72 \mathrm{~h}$ of exposure to GEM concentrations equal to one-half or one-quarter of the IC50. We used cDNA microarrays containing 2976 genes to identify genes with expression affected by exposure to GEM. The self-organizing map identified nine clusters, including 85 and 87 genes, that showed differential expression in response to exposure to one half and one quarter IC50 GEM, respectively. Of these, 24 genes were common to cells exposed to the two different concentrations of GEM. Most are signal transduction or transcription-related genes. The microarray data for two of these genes, SPARC and RPS8, were validated by RT-PCR. Although further studies are needed to examine whether the changes in expression profiles of these genes are specific to cells exposed to GEM, the present data provide insights into the anti-tumor effects of GEM on pancreatic cancers.
\end{abstract}

\section{Introduction}

Pancreatic cancer is a devastating disease with a short survival after diagnosis because of its high metastatic potential $(1,2)$. The development of anti-cancer drugs is necessary for the effective treatment of pancreatic cancer. Gemcitabine (GEM) is a novel nucleoside analogue that has significant anti-tumor activity against various solid tumors, including pancreatic

Correspondence to: Dr Hiroaki Toshimitsu, Department of Surgery II, Yamaguchi University School of Medicine, 1-1-1 Minami-kogushi, Ube 755-8505, Japan

E-mail: h.tosimitu@ogoridaiichi.jp

Key words: pancreatic cancer cell line, cDNA microarray, gemcitabine, cell cycle cancer, head and neck cancer, and non-small cell lung cancer (3-5), and it is more effective than fluorouracil in reducing symptoms in pancreatic cancer patients. Because GEM confers a small survival benefit to patients with pancreatic cancer, it is used as a first-line therapy for patients with advanced pancreatic cancer (6).

GEM does not always induce a complete response in all types of tumors; however, many studies have shown its clinical efficacy in the treatment of pancreatic cancer $(7,8)$. GEM is phosphorylated and metabolized and then incorporated into cellular DNA. As a result, it causes masked chain termination $(9,10)$. GEM sensitivity of cells is known to be affected by pathways that involve ribonucleotide reductase E2F1 and Bcl-2 (11-13). However, these pathways cannot account for all of the biological effects of GEM on cells, and therefore other pathways should be investigated. To clarify the mechanisms by which cell proliferation is perturbed by GEM, it is important to identify genes that show differential expression in response to GEM.

The development of cDNA microarray technology has allowed innovative studies of the levels of expression of thousands of genes with a single experiment. In the present study, we used cDNA microarray technology to investigate the mechanism that underlies the inhibition of cell proliferation by GEM in pancreatic cancer. Given the previous findings that clinical efficacy does not require cytotoxic doses of GEM $(7,8)$, we focused on the effects of lower concentrations of GEM.

\section{Materials and methods}

Cell line and cell cytotoxicity. We used the YPK-1 cell line, which was established from human pancreatic cancer $(15,16)$. YPK-1 cells were maintained in Dulbecco's modified Eagle's medium (Nissui Pharmaceutical, Tokyo, Japan) supplemented with $10 \%$ fetal calf serum, $100 \mathrm{U} / \mathrm{ml}$ penicillin $\mathrm{G}$, and $100 \mu \mathrm{g} / \mathrm{ml}$ streptomycin. GEM was provided by Eli Lilly Research Laboratories (Indianapolis, IN, USA). MTT (assays of YPK-1 cells were performed to evaluate the cytotoxicity of GEM as described previously (14). The 50\% inhibitory concentration (IC50) at $72 \mathrm{~h}$ after treatment was $6.3 \times 10^{-3} \mu \mathrm{g} / \mathrm{ml}$.

Cell growth assay of GEM. To investigate the effect of GEM on the proliferation of YPK-1 cells, we performed cell growth 
$1 \mathrm{~h}$

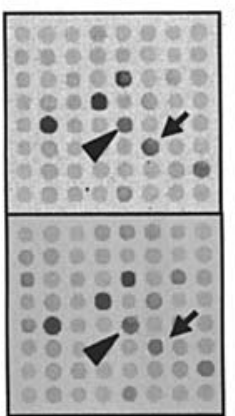

$24 \mathrm{~h}$
$6 \mathrm{~h}$

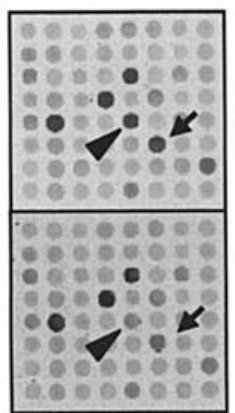

$72 \mathrm{~h}$

Figure 1. Representative images of colorimetric cDNA microarray analysis of YPK-1 cells exposed to half IC50 GEM for 1, 6, 12, 24, and $72 \mathrm{~h}$. Arrowheads and arrows indicate spots corresponding to HSPA 8 and HNRPC, respectively. The images reveal temporal changes in gene expression.

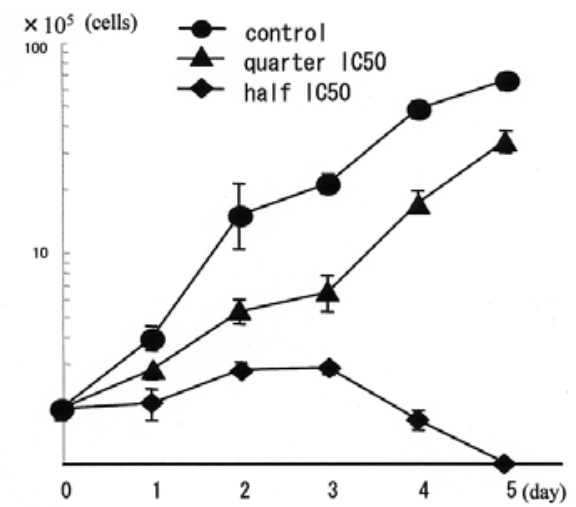

Figure 2. Effects of different concentrations of GEM on proliferation of YPK-1 cells. Cells were incubated with one of three concentrations of GEM: control $(0 \mu \mathrm{g} / \mathrm{ml})$, quarter IC50 $\left(1.6 \times 10^{-3} \mu \mathrm{g} / \mathrm{ml}\right)$, and half IC50 $\left(3.2 \times 10^{-3} \mu \mathrm{g} / \mathrm{ml}\right)$. The proliferation of cells was suppressed in a dose-dependent manner. The growth curves of cells incubated with the different concentrations of GEM were significantly different by one-way ANOVA $(\mathrm{p}<0.0001)$.

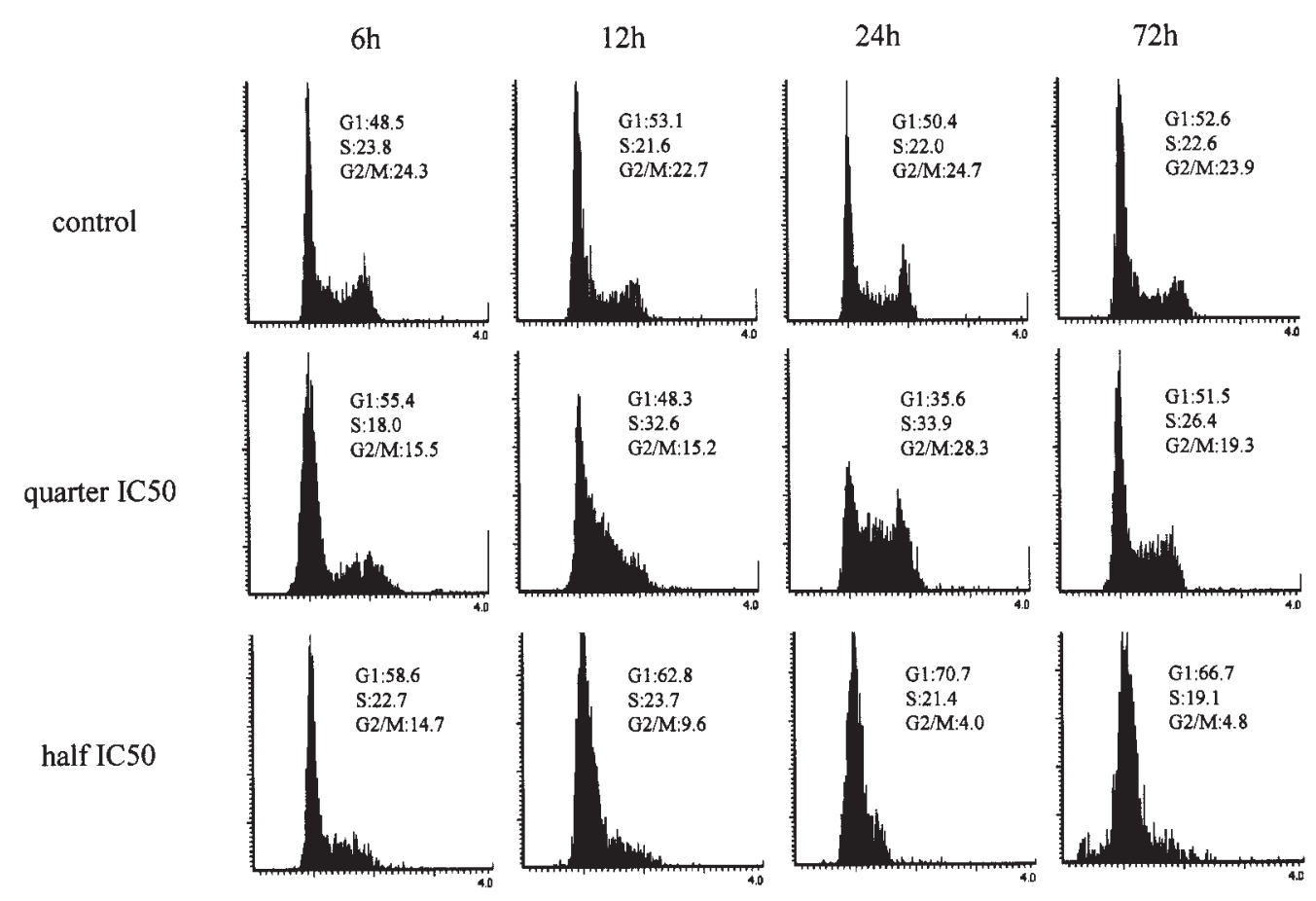

Figure 3. Temporal changes of the cell cycle in different concentrations of GEM. Cell cycle responses to the three concentrations of GEM were analyzed at 6 , 12 , 24, and $72 \mathrm{~h}$ after treatment. Cells exposed to quarter IC50 GEM showed a block in late S phase, and the block appeared to be reversible at 72 h. Cells exposed to half IC50 of GEM increased the number of cells in G1 phase at a relatively early time after treatment with GEM.

assays. YPK-1 cells were collected by trypsinization, and $1 \times 10^{5}$ cells were plated in $2 \times 10 \mathrm{~cm}$ dishes. The cells were allowed to attach overnight and were then exposed to one of three concentrations of GEM, $0 \mu \mathrm{g} / \mathrm{ml}$ (control), $3.2 \times 10^{-3} \mu \mathrm{g} / \mathrm{ml}$ (half IC50), and $1.6 \times 10^{-3} \mu \mathrm{g} / \mathrm{ml}$ (quarter IC50) for 5 days. The number of viable cells was determined by the trypan blue dye exclusion method. Experiments were performed in triplicate, and the mean values of the three experiments were calculated.

Cell cycle analysis. Cells cultured with the three different concentrations of GEM (control, half IC50, and quarter IC50) were harvested at $6,12,24$, and $72 \mathrm{~h}$ after treatment. Cells were stained with propidium iodide and analyzed by laser scanning cytometry (LSC) (LSC2; Olympus Co., Tokyo, Japan) as described previously (17).

cDNA microarray and data analysis. Differential gene expression in response to different concentrations of GEM was examined by cDNA microarray as described previously (14). Briefly, total cellular RNA was extracted with Isogen (Nippon Gene, Tokyo, Japan) from GEM-exposed cells at 1, 6, 12, 24, and $72 \mathrm{~h}$ after treatment. Cy5-dUTP- and Cy3-dUTP(Amersham Biosciences, Piscataway, NJ, USA) labeled probes 
Table I. Primers of RPS8, SPARC, and GAPDH.

\begin{tabular}{llcr}
\hline Gene symbol & Primer sequence & Number of PCR cycle & Product size (bp) \\
\hline RPS8 & 5'-GCCGCATCCACACAGTCCGT-3' & 20 & 264 \\
& 3'-GCTTGGCTCCCTTCTTGCGG-5' & & 310 \\
SPARC & 5'-GGGACTAGAGGCTCAGTGGTG-3' & 21 & 336 \\
GAPDH & 5'-GTCCCTAGAGCCCCTGAGAAG-3' & 18 & 3 \\
& 5'-GCATCCTGGGCTACACTGAG -3' & & \\
\hline
\end{tabular}

were synthesized from total RNA per the manufacturer's protocol. We used a commercially available cDNA microarray, Human Chip version 1.0 (DNA Chip Research, Kanagawa, Japan), which contains 2976 cDNAs. The labeled probes were mixed with a hybridization solution. After hybridization, the slides were washed five times. Slides were scanned with a GenePix 4000 scanner (Axon Instruments, Union City, CA, USA). The fluorescence intensity of spot was compared to the local background, and background subtraction was performed. To normalize the data, the fluorescence ratio for each gene was adjusted to a median ratio value of all spots in the array of 1.0. Spots for which the ratio of the backgroundsubtracted signal intensity to the local background was less than 3 were excluded from analysis. The ratios of each spot in duplicate experiments were averaged. Genes were categorized as temporal and significant profile changes if the ratio difference was 2.5-fold or greater for at least one time point, as shown in Fig. 1. Self-organizing map (SOM) analysis was performed with DNASIS Stat (DNA Chip Research). A threerow by three-column SOM was generated with an initial learning rate of 0.5 and an initial neighborhood size of 10 .

RT-PCR analysis. To validate our microarray results for the SPARC and RPS8 genes, we carried out RT-PCR of these genes with the same RNAs used for the initial screening. The reverse transcriptase step was performed as described previously (14). Five microliters of cDNA solution (equivalent to the cDNA from $100 \mathrm{ng}$ of initial RNA) was amplified in $45 \mu \mathrm{l}$ of PCR mixture containing $25 \mathrm{pmol}$ of each primer for each target gene. Each cycle consisted of denaturation at $94^{\circ} \mathrm{C}$ for $1 \mathrm{~min}$, annealing at $61^{\circ} \mathrm{C}$ for $45 \mathrm{sec}$, and elongation at $72^{\circ} \mathrm{C}$ for $2 \mathrm{~min}$. PCR protocols, primer sequences, and expected product sizes are shown in Table I. PCR products were separated by electrophoresis on $2.0 \%$ agarose gels and visualized by UV irradiation after ethidium bromide staining.

Statistical analysis. All data are presented as mean \pm SE. Statistical analyses were performed with repeated measures one-way analysis of variance (ANOVA) with StatView software (SAS Institute, Cary, NC, USA). Significance was defined as a $\mathrm{p}$ value of $<0.05$.

\section{Results}

Perturbation of cell proliferation by GEM. We first investigated how distinct concentrations of GEM affect the proliferation of YPK-1 cells. The growth curves differed significantly between the two concentrations in a dose-dependent manner $(\mathrm{p}<0.0001)$ (Fig. 2).

Influence of GEM on cell cycle progression. Changes in the cell cycle in response to different concentrations of GEM are shown in Fig. 3. A DNA histogram of control cells was almost unchanged from $6 \mathrm{~h}$ to $72 \mathrm{~h}$ after exposure of cells to GEM. Exposure of cells to quarter IC50 caused an accumulation of cells in the $\mathrm{S}$ phase between 12 and $24 \mathrm{~h}$ after exposure. This DNA histogram pattern had returned to normal by $72 \mathrm{~h}$ after exposure. In contrast, exposure of cells to half IC50 increased the number of cells in the G1 phase at $6 \mathrm{~h}$ after GEM exposure, and this was accompanied by a small sub-G1 peak at $72 \mathrm{~h}$ and appeared to lead into apoptosis.

Gene expression analysis by SOM in YPK-1 cells exposed to $G E M$. Genes were subjected to cluster analysis and a ninepartition SOM with a $3 \times 3$ algorithm (Fig. 4, Tables II and III). The resulting clusters were independent of the biological functions of the selected genes. The analysis revealed temporal changes in the expression of genes related to the cell cycle, transporter or immune response. The genes appeared to reflect the cellular response to GEM. We identified 24 genes whose expression altered in response to two different concentrations of GEM. The expression level of most genes was unchanged in cells exposed to either half IC50 or quarter IC50 of GEM for $24 \mathrm{~h}$.

Validation of microarray data by RT-PCR. To validate the microarray data, we carried out RT-PCR of SPARC and RPS8, two genes selected randomly from the genes showing differential expression in response to GEM. The temporal changes in expression of the genes were consistent with the corresponding SOM patterns (Fig. 5). Thus, the microarray data were validated by the RT-PCR results.

\section{Discussion}

GEM blocks cell cycle progression in cells at the appropriate concentration (18). In the present study, G1 arrest was observed in cells exposed to half IC50 of GEM, and subG1 was observed in cells exposed to GEM for $72 \mathrm{~h}$. It was anticipated that cells with suppressed proliferation would undergo apoptosis after $72 \mathrm{~h}$ (day 3). These observations were consistent with the findings of our growth assay (Fig. 1). 
A

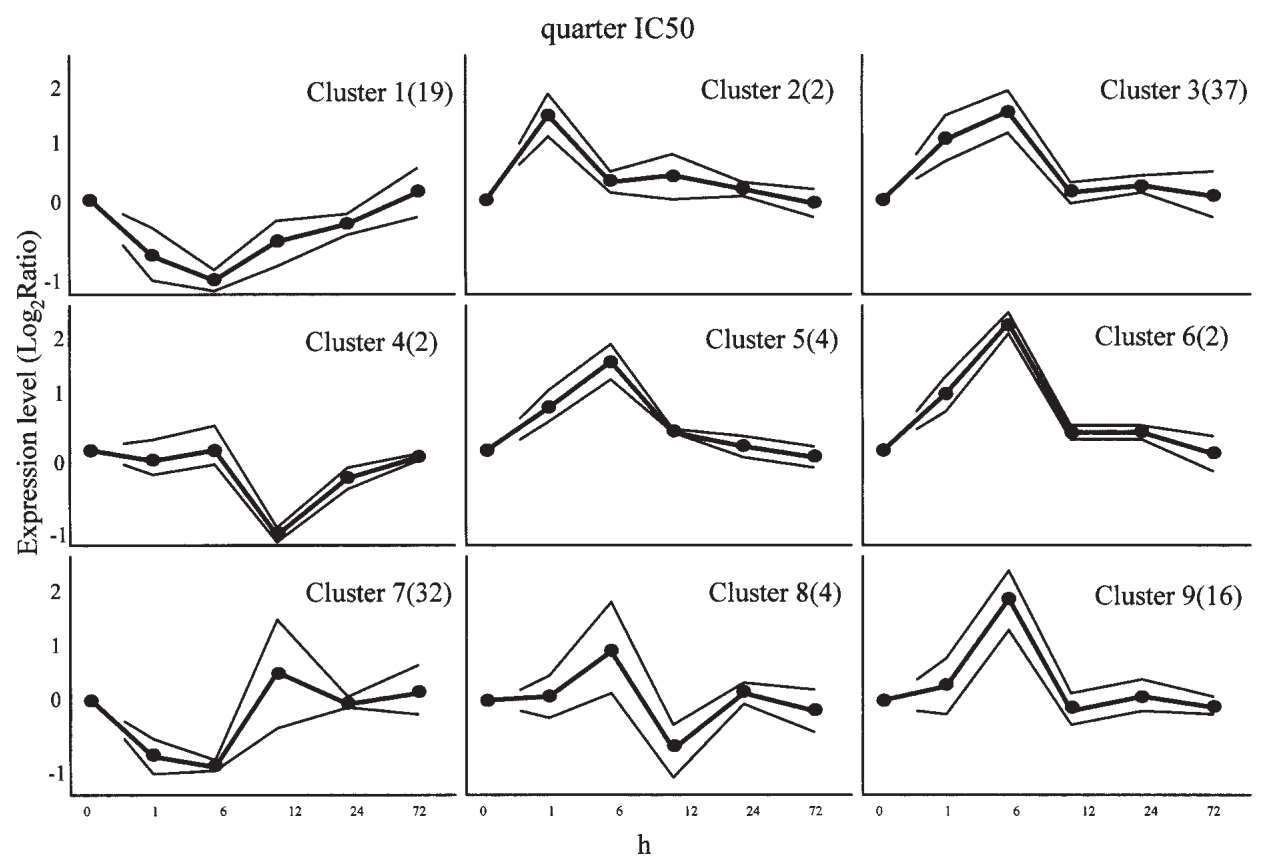

B

half IC50



Figure 4. Nine-partition SOM showing temporal changes in expression in cells exposed to GEM. Approximately 90 genes for cells exposed to GEM (A, quarter IC50; B, half IC50) were identified with the criteria described above. Thick lines and dots indicate the average expression levels for each gene cluster. Thin lines indicate the standard error for each time point. The number in the top right corner of each panel represents the number of genes in the cluster.

Cells exposed to quarter IC50 of GEM temporarily accumulated in late $\mathrm{S}$ phase, indicating that progression through $\mathrm{S}$ phase might be delayed. At $72 \mathrm{~h}$ of exposure, there was no significant difference between the quarter IC50 and the control. Thus, a low concentration of GEM prolongs the $\mathrm{S}$ phase of YPK-1 cells. It is intriguing to investigate a set of genes linked with a difference in the cellular response to GEM. Thus, it is important to focus on the change of gene expression caused by different GEM concentrations.

Genes relevant to cell cycle regulation were identified by generation of SOMs for data from cells treated with GEM. In half IC50-treated cells, CDKN1B, a cyclin-dependent kinase inhibitor implicated in the transition from proliferation to a quiescent state $(19,20)$, was classified to cluster 2 , and the

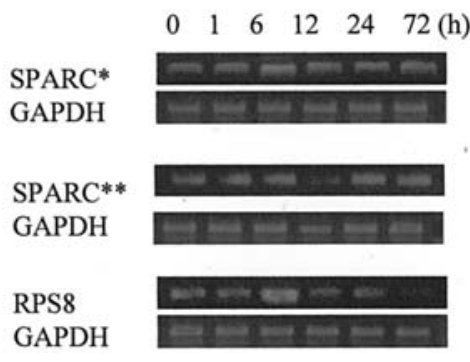

Figure 5. Validation of microarray data by RT-PCR. Temporal changes in expression of the SPARC and RPS 8 genes were consistent with the corresponding SOM patterns. SPARC ${ }^{*}$, expression changes of cluster 8 in half IC50; SPARC ${ }^{* *}$, cluster 8 in quarter IC50; and RPS8, cluster 6 in half IC50. Glyceraldehyde-3-phosphate dehydro-genase (GAPDH) expression is shown as a control. 
Table II. Temporal changed genes in half IC50.

\begin{tabular}{|c|c|c|c|c|c|}
\hline Symbol & Unigene & Symbol & Unigene & Symbol & Unigene \\
\hline \multicolumn{6}{|l|}{ Cluster 1} \\
\hline NEDF & Hs.512608 & MAN1B1 & Hs.279881 & PABPN1 & Hs.117176 \\
\hline TAF15 & Hs.402752 & PPIA & Hs.356331 & SERF2 & Hs.424126 \\
\hline SOLH & Hs.416262 & LYPLA2 & Hs.413781 & BCL2L1 & Hs.305890 \\
\hline SMARCD $^{\mathrm{a}}$ & Hs.250581 & NYD-SP15 & Hs.388220 & $\mathrm{CCT} 2$ & Hs.189772 \\
\hline GPSN2 & Hs.306122 & TAGLN2 & Hs.406504 & MSF & Hs.363475 \\
\hline $\mathrm{SRRM}^{\mathrm{a}}$ & Hs.433343 & AP2A1 & Hs.296426 & IGKC & Hs.377975 \\
\hline GRN & Hs.180577 & & & & \\
\hline \multicolumn{6}{|l|}{ Cluster 2} \\
\hline PLA2G4C & Hs. 18858 & CDKN1B & Hs.238990 & NUCKS $^{a}$ & Hs.510265 \\
\hline DDX21 & Hs.169531 & MSH6 & Hs.445052 & & \\
\hline \multicolumn{6}{|l|}{ Cluster 3} \\
\hline $\mathrm{TPT}^{\mathrm{a}}$ & Hs.374596 & HNRPC & Hs.476302 & TRA1 & Hs.192374 \\
\hline $\mathrm{RPL7}^{\mathrm{a}}$ & Hs.421257 & TAP1 $^{\mathrm{a}}$ & Hs.352018 & PA2G4 & Hs.374491 \\
\hline PAI-RBP1 & Hs.356427 & RPL19a & Hs.381061 & $\mathrm{IF} 2$ & Hs.158688 \\
\hline $\mathrm{ALK}^{\mathrm{a}}$ & Hs.410680 & & & & \\
\hline \multicolumn{6}{|l|}{ Cluster 4} \\
\hline HLA-B & Hs.77961 & $\mathrm{NOLC}^{\mathrm{a}}$ & Hs.75337 & GDI1 & Hs.74576 \\
\hline HLA-A & Hs.181244 & C2orf6 & Hs.196437 & COPZ1 & Hs.181271 \\
\hline FXYD5 & Hs.333418 & GPX4 & Hs.433951 & & \\
\hline \multicolumn{6}{|l|}{ Cluster 5} \\
\hline АСТВ & Hs.426930 & RPS27A & Hs.311640 & HNRPD & Hs.438726 \\
\hline CAP1 & Hs.104125 & & & & \\
\hline \multicolumn{6}{|l|}{ Cluster 6} \\
\hline $\mathrm{PABPC}^{\mathrm{a}}$ & Hs.387804 & RPS8 & Hs.512675 & TCP1 & Hs.4112 \\
\hline HNRPA1 & Hs.356721 & $\mathrm{RPS} \mathrm{A}^{\mathrm{a}}$ & Hs.356572 & HSPA $^{\mathrm{a}}$ & Hs.180414 \\
\hline HSPC016 & Hs.356440 & RPS6 $^{a}$ & Hs.408073 & RPL5 $^{\mathrm{a}}$ & Hs.469653 \\
\hline EIF3S3 & Hs.127149 & & & & \\
\hline \multicolumn{6}{|l|}{ Cluster 7} \\
\hline MAT2A & Hs.77502 & ANXA6 ${ }^{a}$ & Hs.412117 & PHGDH & Hs.3343 \\
\hline PSAPa $^{a}$ & Hs.406455 & PPAP2A & Hs.482121 & HLA-F & Hs.411958 \\
\hline GNAI2 & Hs.77269 & $\mathrm{FUS}^{\mathrm{a}}$ & Hs.107720 & & \\
\hline \multicolumn{6}{|l|}{ Cluster 8} \\
\hline ATP1A1 & Hs.371889 & $\mathrm{BZW} 1^{\mathrm{a}}$ & Hs.355983 & EEF1G & Hs.256184 \\
\hline SPARC $^{a}$ & Hs.111779 & RALBP1 & Hs.75447 & ENO1 & Hs.433455 \\
\hline ATF4 & Hs.181243 & SFRS5 $^{\mathrm{a}}$ & Hs.166975 & TEGT & Hs.35052 \\
\hline FTL & Hs.433670 & & & & \\
\hline \multicolumn{6}{|l|}{ Cluster 9} \\
\hline EEF1A1 ${ }^{a}$ & Hs.439552 & YWHAZ $^{\mathrm{a}}$ & Hs.386834 & EIF4A2 & Hs.511904 \\
\hline $\mathrm{ARPC}^{\mathrm{a}}$ & Hs.126222 & N4BP1 & Hs.323712 & UBE2V1 & Hs.381025 \\
\hline H19 & Hs.415722 & DDX5 & Hs.279806 & EEF1A1L14a & \\
\hline GNAS & Hs.157307 & ARHA & Hs.77273 & & \\
\hline
\end{tabular}

${ }^{\mathrm{a}}$ Gene symbols are common in quarter IC50. 
Table III. Temporal changed genes in quarter IC50.

\begin{tabular}{clcccc}
\hline Symbol & Unigene & Symbol & Unigene & Symbol \\
\hline Cluster 1 & & & & \\
GCN5L2 & Hs.101067 & C12ORF8 & Hs.511762 & HSCARG & Hs.288969 \\
RPS2 & Hs.498569 & CAPZB & Hs.333417 & YARS & Hs.239307 \\
BST2 & Hs.118110 & ARHC & Hs.179735 & MBTPS1 & Hs.75890 \\
PSAP & Hs.406455 & CYFIP2 & Hs.211201 & ANXA6 & Hs.412117 \\
RBBP2 & Hs.76272 & STAT1 & Hs.21486 & SFRS5 & Hs.166975 \\
PSMD1 & Hs.3887 & KIAA1161 & & &
\end{tabular}

Cluster 2

$\begin{array}{lll}\text { PSMB6 Hs.77060 EEF1B2 } & \text { H }\end{array}$

Cluster 3

TPT1

TPI1

$\mathrm{CHP}$

RPS17

EEF1A1 ${ }^{a}$

UBB

RPL26

RPL32

KIAA1228

Hs.374596

Hs.512711

Hs.406234

Hs. 433427

Hs.439552

Hs.356190

Hs.406682

Hs. 265174

Hs.388073

Cluster 4

YWHAZ

Hs.386834

$\mathrm{BZW1}^{\mathrm{a}}$

Hs.381123

Hs.79141

Hs. 180909

Hs.374334

CCT4

RPL $7^{\mathrm{a}}$

UREB 1

H2AFZ

RPS24

Hs.311609

RTN4

Hs.436349

LAMR1

Hs. 374553

Cluster 6

PPP1R8

Hs.356590

$\mathrm{ALK}^{\mathrm{a}}$

Hs. 410680

Cluster 7

$\begin{array}{ll}\text { ZFP289 } & \text { Hs.436204 } \\ \text { PTDSS2 } & \text { Hs.12851 } \\ \text { SMARCD2a } & \text { Hs.250581 } \\ \text { PIGT } & \text { Hs.437388 } \\ \text { SRRM2 }^{a} & \text { Hs.433343 } \\ \text { NUCKS }^{a} & \text { Hs.510265 } \\ \text { PDCD11 }_{\text {KIAA1171 }} & \text { Hs.239499 } \\ & \text { Hs. } 353087\end{array}$

Cluster 8

$\begin{array}{ll}\text { ARPC5 }^{\text {a }} & \text { Hs.126222 } \\ \text { SPARC }^{\text {a }} & \text { Hs.111779 }\end{array}$

Cluster 9

\begin{tabular}{lccccc} 
PABPC1 $^{\text {a }}$ & Hs.387804 & RPL13 & Hs.410817 & RPL13A & Hs.449070 \\
HSPA8 $^{\mathrm{a}}$ & Hs.180414 & RPS3A $^{\mathrm{a}}$ & Hs.356572 & BTF3 & Hs.446567 \\
TAP1 $^{\mathrm{a}}$ & Hs.352018 & RPS6 $^{\mathrm{a}}$ & Hs.408073 & RPL5 $^{\mathrm{a}}$ & Hs.469653 \\
EEF1A1L14 $^{\mathrm{a}}$ & & & & \\
\hline
\end{tabular}

${ }^{\mathrm{a}}$ Gene symbols are common in half IC50.

$\begin{array}{cl}\text { GADD45B } & \text { Hs. } 110571 \\ \text { EIF4G2 } & \text { Hs. } 183684 \\ \text { FLJ13855 } & \text { Hs. } 369120 \\ \text { SARS } & \text { Hs. } 444261 \\ \text { FLJ20542 } & \text { Hs. } 6449 \\ \text { ABCB1 } & \text { Hs. } 21330 \\ \text { KIAA1533 } & \text { Hs. } 365476\end{array}$

RPL9

Hs.412370

SH3BGRL

Hs. 14368

$\begin{array}{cl}\text { TLN1 } & \text { Hs.375001 } \\ \text { ACTN4 } & \text { Hs.443619 } \\ \text { KIAA0892 } & \text { Hs.112751 } \\ \text { NDP52 } & \text { Hs.154230 } \\ \text { SERHL } & \text { Hs.398085 } \\ \text { NOLC1 }^{\text {a }} & \text { Hs.75337 } \\ \text { FUS }^{\mathrm{a}} & \text { Hs.107720 }\end{array}$

\section{RPS18 Hs.275865}

Hs.408054

RPLP1 Hs.356502

FTH1

RPS5

RPL19

Hs.381061

Hs.181163

$\begin{array}{cc}\text { RPL12 } & \text { Hs.408054 } \\ \text { NTRK1 } & \text { Hs.406293 } \\ \text { RPLP1 } & \text { Hs.356502 } \\ \text { FTH1 } & \text { Hs. } 167344 \\ \text { RPS5 } & \text { Hs.378103 } \\ \text { RPL19a } & \text { Hs.381061 } \\ \text { HMGN2 } & \text { Hs. } 181163\end{array}$


expression level slowly increased until $12 \mathrm{~h}$ after GEM exposure. Elevated expression of CDKN1B may cause G1 arrest of cells. Although other genes showed changes in expression levels in the present study, the roles of these genes in the anti-proliferative activity of GEM remain to be clarified.

Genes encoding transporters or proteins involved in immune responses showed altered expression more frequently in cells exposed to half IC50 than in cells exposed to quarter IC50. GPX4 encodes glutathione peroxidase 4 , which protects cells against oxidative damage by anti-cancer drugs $(21,22)$. ATP1A1 encodes an $\mathrm{Na}^{+} / \mathrm{K}^{+}$transporter and is associated with the accumulation of drugs such as anti-cancer agents (23). The expression of $\mathrm{ABCB} 1$, an $\mathrm{ABC}$ transporter that influences sensitivity to anti-cancer agents (24), was temporarily decreased in cells exposed to quarter IC50. In contrast, the expression of genes encoding ribosome-related proteins was altered more frequently in cells exposed to quarter IC50 than in cells exposed to half IC50. The present data suggest that the expression of ribosomal proteins is linked to the susceptibility of tumor cells to chemotherapy $(14,25,26)$. However, cellular responsiveness to a drug is dependent on the concentration of the drug because different genes are affected by different concentrations of drugs.

In the present study, 24 genes showed altered expression in response to both concentrations of GEM. In most of them, gene expression patterns in hierarchical cluster analysis were not affected by GEM concentrations (data not shown). It is likely that the changes in expression are not related to the inhibitory effects of GEM on cell proliferation. However, the level of expression of 2 of the 24 genes was dependent on the concentration of GEM. Temporal changes in the expression of these genes, SPARC (cluster 8 in half IC50 and cluster 8 in quarter IC50) and YWHAZ (cluster 9 in half IC50 and cluster 4 in quarter IC50), may be regulated by different molecular pathways that respond to varying concentrations of GEM. We believe that genes showing dose-dependent responses to GEM are associated with cell proliferation.

In conclusion, the gene expression profiles from cDNA microarray analysis coupled with SOM analysis revealed the molecular responses of YPK-1 cells to different concentrations of GEM. Identification of GEM-responsive genes provides insights into the anti-cancer mechanism of GEM and has the potential for clinical use to predict cellular responses to GEM. Further studies are needed to confirm that the genes identified in the present study are associated with growth inhibition in response to GEM.

\section{References}

1. Beger HG, Rau B, Gansauge F, Poch B and Link KH: Treatment of pancreatic cancer: challenge of the facts. World J Surg 27: 1075-1084, 2003

2. Xu Z, Friess H, Solioz M, Aebi S, Korc M, Kleeff J and Buchler MW: Bcl-x(L) antisense oligonucleotides induce apoptosis and increase sensitivity of pancreatic cancer cells to gemcitabine. Int J Cancer 94: 268-274, 2001.

3. Carmichael J: The role of gemcitabine in the treatment of other tumours. Br J Cancer 78: 21-25, 1998.

4. Storniolo AM, Allerheiligen SR and Pearce HL: Preclinical, pharmacologic, and phase I studies of gemcitabine. Semin Oncol 24: S7-2-S7-7, 1997.

5. Steward WP: Combination studies with gemcitabine in the treatment of non-small-cell lung cancer. Br J Cancer 78: 15-19, 1998.
6. Mok TS and Leung TW: Changes in chemotherapy for pancreatic cancer. Hong Kong Med J 5: 367-374, 1999.

7. Brodowicz T, Kostler WJ, Moslinger R, Tomek S, Vaclavik I, Herscovici V, Wiltschke C, Steger GG, Wein W, Seifert M, Kubista E and Zielinski CC: Single-agent gemcitabine as second- and third-line treatment in metastatic breast cancer. Breast 9: 338-342, 2000.

8. Ziske C, Schlie C, Gorschluter M, Glasmacher A, Mey U, Strehl J, Sauerbruch T and Schmidt-Wolf IG: Prognostic value of CA 19-9 levels in patients with inoperable adenocarcinoma of the pancreas treated with gemcitabine. Br J Cancer 89: 1413-1417, 2003.

9. Plunkett W, Huang P, Xu YZ, Heinemann V, Grunewald R and Gandhi V: Gemcitabine: metabolism, mechanisms of action, and self-potentiation. Semin Oncol 22: 3-10, 1995.

10. Heinemann V, Hertel LW, Grindey GB and Plunkett W: Comparison of the cellular pharmacokinetics and toxicity of 2',2'-difluorodeoxycytidine and 1-beta-D-arabinofuranosylcytosine. Cancer Res 48: 4024-4031, 1988.

11. Rodicker F, Stiewe T, Zimmermann S and Putzer BM: Therapeutic efficacy of E2F1 in pancreatic cancer correlates with TP73 induction. Cancer Res 61: 7052-7055, 2001.

12. Renner K, Amberger A, Konwalinka G, Kofler R and Gnaiger E: Changes of mitochondrial respiration, mitochondrial content and cell size after induction of apoptosis in leukemia cells. Biochim Biophys Acta 1642: 115-123, 2003.

13. Kikuchi T, Daigo Y, Katagiri T, Tsunoda T, Okada K, Kakiuchi S, Zembutsu H, Furukawa Y, Kawamura M, Kobayashi K, Imai K and Nakamura Y: Expression profiles of non-small cell lung cancers on cDNA microarrays: identification of genes for prediction of lymph-node metastasis and sensitivity to anticancer drugs. Oncogene 22: 2192-2205, 2003.

14. Toshimitsu H, Hashimoto K, Tangoku A, Iizuka N, Yamamoto K, Kawauchi S, Oga A, Furuya T, Oka M and Sasaki K: Molecular signature linked to acquired resistance to cisplatin in esophageal cancer cells. Cancer Lett 211: 69-78, 2004.

15. Suzuki N, Maeda Y, Tanaka S, Hida N, Mine T, Yamamoto K, Oka $\mathrm{M}$ and Itoh $\mathrm{K}$ : Detection of peptide-specific cytotoxic Tlymphocyte precursors used for specific immunotherapy of pancreatic cancer. Int J Cancer 98: 45-50, 2002

16. Iizuka N, Oka M, Yamamoto K, Tangoku A, Miyamoto K, Miyamoto T, Uchimura S, Hamamoto $\mathrm{Y}$ and Okita K: Identification of common or distinct genes related to antitumor activities of a medicinal herb and its major component by oligonucleotide microarray. Int J Cancer 107: 666-672, 2003.

17. Furuya T, Kamada T, Murakami T, Kurose A and Sasaki K: Laser scanning cytometry allows detection of cell death with morphological features of apoptosis in cells stained with PI. Cytometry 29: 173-177, 1997.

18. Sun D, Urrabaz R, Kelly S, Nguyen M and Weitman S: Enhancement of DNA ligase I level by gemcitabine in human cancer cells. Clin Cancer Res 8: 1189-1195, 2002.

19. Polyak K, Lee MH, Erdjument-Bromage H, Koff A, Roberts JM, Tempst $\mathrm{P}$ and Massague J: Cloning of p27Kip1, a cyclindependent kinase inhibitor and a potential mediator of extracellular antimitogenic signals. Cell 78: 59-66, 1994.

20. Bruni P, Boccia A, Baldassarre G, Trapasso F, Santoro M, Chiappetta G, Fusco A and Viglietto G: PTEN expression is reduced in a subset of sporadic thyroid carcinomas: evidence that PTEN-growth suppressing activity in thyroid cancer cells mediated by p27kip1. Oncogene 19: 3146-3155, 2000.

21. Kelland LR: New platinum antitumor complexes. Crit Rev Oncol Hematol 15: 191-219, 1993.

22. Wolf CR, Hayward IP, Lawrie SS, Buckton K, McIntyre MA, Adams DJ, Lewis AD, Scott AR and Smyth JF: Cellular heterogeneity and drug resistance in two ovarian adenocarcinoma cell lines derived from a single patient. Int J Cancer 39: 695-702, 1987.

23. Gately DP and Howell SB: Cellular accumulation of the anticancer agent cisplatin. Br J Cancer 67: 1171-1176, 1993.

24. Borst P, Evers R, Kool M and Wijnholds J: A family of drug transporters: the multidrug resistance-associated proteins. J Natl Cancer Inst 92: 1295-1302, 2000.

25. Hu ZB, Minden MD, McCulloch EA and Stahl J: Regulation of drug sensitivity by ribosomal protein S3a. Blood 95: 1047-1055, 2000 .

26. Khanna N, Sen S, Sharma H and Singh N: S29 ribosomal protein induces apoptosis in H520 cells and sensitizes them to chemotherapy. Biochem Biophys Res Commun 304: 26-35, 2003. 